\title{
Linfocitosis Aguda Infecciosa.
}

\author{
Dra. Myriam Campbell B., Dra. Mireya Bravo L. ${ }^{1}$
}

Acute Infectious Lymphocytosis.

\begin{abstract}
Acute Infectious Lymphocy tosis is an infrecuent clinical entity with non especific and variable symptoms; probably it has a viral etiology and its most important facts are hyperleucocitosis and absolute lymphocy tosis.

Lymphocytosis explains difficulties in the differential diagnosis with malignant diseases, especially acute lymphoblastic leukemia. Three cases are reported.
\end{abstract}

La Linfocitosis aguda infecciosa (LAI) fue descrita en 1941 por Carl Smith como "una entidad de etiología desconocida, infectoconta. giosa, que se presenta tanto en forma esporádica como epidémica". 1 .

Es una enfermedad poco conocida por su baja frecuencia y manifestaciones leves, de curso autolimitado y de evolución benigna. Se presenta en niffos $y$ adultos jóvenes.

El diagnóstico es de laboratorio ya que el hecho fundanental es una hiperleucocitosis dada por linfocitosis. A pesar que esta linfocitosis es producida por linfocitos pequeños, normales, suele ser de dificil interpretación, ya que para ello deben tomarse en cuenta tanto las características hematopoyéticas fisiológicas de la edad, como diversas entidades que evolucionan con linfocitosis absolutas de igual magnitud.

Los hechos anteriores, unidos a los escasos datos de la literatura nacional, nos motivaron para hacer esta revisión clínica, llamar la atención sobre este cuadro, tratar de precisar algunas características y recoger la información actual al respecto.

\section{MATERIAL}

Se revisan 3 casos clínicos que se presentaron en la Sección de Hematología del Hospital Roberto del Río.

CASO 1.- D.G.A. 4 1/2 meses. Varón.

Lactante con desnutrición energético proteica grado 11 que se hospitalizó por diarrea con deshidratación y fiebre de 3 días de evolución. Examen físico: febril, deshidratado, roncus pulmonares, sin visceromegalia ni adenopatías. En el hemograma se encontró leucocitosis dada por lin. focitos pequeños, el coprocultivo no mostró gérmenes patógenos. Por evolución tórpida se trató con antibióticos y evolucionó favorablemente. El hemograma de control a los 6 dias fue normal. Tabla 1.

Tabla 1.

Resultados y evolución de los exámenes hematológioos

\begin{tabular}{|c|c|c|c|c|c|c|c|c|c|}
\hline & \multicolumn{2}{|c|}{ CASO No 1} & \multirow[b]{2}{*}{$25 /$ VIU } & \multicolumn{2}{|c|}{ CASO NO 2} & \multicolumn{4}{|c|}{ CASO NO 3} \\
\hline & $23 / \mathrm{IV}$ & $29 / \mathrm{IV}$ & & $30 /$ VII & $14 / I X$ & $3 / X$ & II/IV & $17 / \mathrm{N}$ & $2 / \mathrm{V}$ \\
\hline Leucocitos $\mathrm{x} \mathrm{mm}^{3}$ & 88.200 & 15.100 & 64.000 & 16.850 & 8.100 & 5.700 & 42.500 & 30.300 & 4.700 \\
\hline Basófïlos & 0 & 1 & 0 & 0 & 0 & 0 & 0 & 0 & 0 \\
\hline Eosinófilos & 0 & 0 & 4 & 3 & 4 & 2 & 0 & $\mathbf{0}$ & 6 \\
\hline Baciliformes & 3 & 7 & 1 & 0 & 2 & 6 & 2 & 1 & 14 \\
\hline Segmentados & 6 & 36 & 13 & 32 & 45 & 26 & 16 & 12 & 27 \\
\hline Linfocitos & 90 & 50 & 81 & 63 & 47 & 64 & 80 & 86 & 50 \\
\hline Monocitos & 1 & 6 & 1 & 2 & 2 & 2 & 2 & $\mathbf{I}$ & 3 \\
\hline
\end{tabular}

1 Departamento de Pediatría, División Ciencias Médicas Norte. Facultad de Medicina de la Universidad de Chile. Hospital Roberto del Río. 
CASO 2.- M.A.L. 4 años. Mujer.

Sin antecedentes mórbidos: Dos días de evolución con fiebre, vómitos, dolor periumbilical $\mathrm{y}$ diarrea, por lo que se solicitó hemograma e indicó Cloramfenicol (que recibió durante dos días). Examen Físico: Eutrófica, afebril, roncus y estertores pulmonares, sin adenopatia, ri visceromegalia. Hemograma con leucocitosis dada por linfocitos pequeños. Al 50 día de evolución, afebril, escasos roncus y franca disminución de la linfocitosis. A los 20 dias estaba sana con Hemograma normal. El estudio virológico de secreción faríngea y deposiciones fue negativo para adenovirus y coxsackie $B$.

Tres semanas después nuevamente febril, roncus, estertores pulmonares, hemograma con linfocitosis relativa por linfocitos medianos. Tabla 1.

\section{CASO 3.- J.F.M. 3 atoos. Varón.}

Preescolar con desnutrición energético proteica grado II y enfermedad celíaca. Un día con diarrea, fiebre, falta de ánimo y dolor abdominal difuso. Examen físico: sin visceromegalia ni adenopatías. Hemograma con leucocitosis por linfocitos pequeños. Mielograma mostró aumento en el porcentaje de linfocitos maduros (30\%). Evolucionó bien, a los 6 dias persistia la linfocitosis pero habian cedido los síntomas. El estudio virológico en secre. ción faríngea y deposiciones fue negativo para virus polio, coxsackie B., adenovirus y herpes. A los 20 días nuevamente febril con tos y roncus pulmonares, hemograma normal. Tabla 1.

En resumen se trata de 2 preescolares y un lactante con fiebre y diarrea; dos de ellos tuvieron roncus y estertores pulmonares, sin visceromegalia ni adenopatias. Hemograma con leucocitosis por aumento de linfocitos pequeños que se normalizó antes de 3 semanas.

\section{COMENTARIO}

Al definir la L A I señalamos como hecho fundamental la presencia de linfocjtosis absoluta.

En pediatría es útil precisar las cifras de recuento absoluto de linfocitos a partir de las cuales se considera que existe linfocitosis, pues estas varian de acuerdo con la edad. Tabla 2.

\section{Tabla 2.}

Valores normalus de leucucitos, y proprorción de reutrófilos linfocitos en sangre periferica setún la edad.

\begin{tabular}{|c|c|c|c|c|}
\hline & \multicolumn{2}{|c|}{ Leucocjtos $x \mathrm{~mm}^{3}$} & \multicolumn{2}{|c|}{ Fórmula \% } \\
\hline & $\bar{x}$ & Rango & NeutróGlos & Linfocitos \\
\hline R.N. & 18.000 & $(10-30.000)$ & 60 & 30 \\
\hline 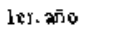 & 11.000 & $(6-18.000)$ & 30 & 60 \\
\hline $2-5$ aก็ั0 & 10.000 & $(6-15.000)$ & 40 & 50 \\
\hline $6-12$ aก̂os & 8.000 & $(5-13.000)$ & 50 & 40 \\
\hline
\end{tabular}

$\mathrm{X}$ : Promedio
Hablamos de linfocitosis absoluta cuando el número de leucocitos por $\mathrm{mm}^{3}$ está aumentado a expensas de un aumento en el número de linfocitos, como sucedjó en nuestros enfermos en que los recuentos de leucocitos fluctuaron entre $42.500 \mathrm{y}$ 88.200 y el porcentaje de linfocitos entre $80 \%$ y $90 \%$.

Las causas más corrientes de linfocitosis absoluta se encuentran en Tabla 3.

\section{Tabla 3.}

\section{Causas de linfocitosis absoluta}

1. Mononucleosis infeccios

2. Linfocitosis infecciosa

3. Infección citomegálica en adultos

4. Infección a Bordetella Pertussis

5. Infección por Toxoplasma gondii

6. Leucemia linfática aguda y crónica

7. Reacciones de hipersensibilidad

Esta forma de linfocitosis hay que distinguirla de las infocitosis relativas, que son aquellas en que el porcentaje de linfocitos de la fórmula diferencial está aumentado, pero se acompaña de recuentos de leucocitos normales, bajos o muy poco aumenta. dos. Estas formas clínicas de linfocitosis son las más frecuentes. Las causas de estas linfocitosis relativas se presentan en la Tabla 4 .

Tabla 4.

Causas de linfocitosis relativas

1. Agranulocitosis

2. Infecciones virales:

Sarampión

Parotiditis infecciosa

Hepatitis

3. Período de convalescencia de infecciones agudas

4. Algunas infecciones crónicas:

Brucelosis

Tuberculosis

Sífilis secundaria y congénita.

Nuestros enfermos aparecieron como casos esporádicos, pero pueden hacerlo en forma epidémica. En una institución para deficientes mentales se observó un brote epidémico que duró 4 meses. El estudio de estos casos sugirió un mecanismo de transmisión por contactos de persona a persona, con un período de incubación entre 12 y 20 días $^{3-3}$.

Los síntomas no permiten caracterizar un síndrome clínico, ya que son variados y de poca intensidad. En nuestros enfermos predominaron las manifestaciones digestivas, siendo la diarrea la más frecuente, dolor periumbilical en un caso y algunas manifestaciones generales como fiebre $y$ cefalea.

En 2 enfermos se encontraron signos de irrita. ción bronquial de poca intensidad, que permiten 
diferenciarlos clínicamente de la coqueluche.

En la literatura se describen además, enupciones cutáneas de tipo morbiliforme generalizada o herpética ${ }^{4}$; infecciones respiratorias altas; faringe enrojecida; irritabilidad; vértigo y aun signos de meningoencefalitis.

El líquido cefalorraquideo puede tener pleocitosis con aumento de linfocitos, a veces simulando poliomielitis ${ }^{3}$.

Un hecho negativo útil en el diagnóstico es la ausencia de adenopatías importantes y esplenomegalia.

Las manifestaciones hematológicas están dadas por leucocitosis a expensas de linfocitos pequeños de aspecto maduro que persisten por 3 a 7 semanas. En águnos casos se acompañan de eosinofilia moderada. No hay anemia ni trombocitopenia.

Ed mielograma muestra un aumento del $30 \%$ o más en la proporción de linfocitos maduros ${ }^{2}$.

En la biopsia ganglionar se encuentra degeneración de los foliculos y proliferación del retículoendotelio 5 .

Las pruebas de aglutinación heterófila son negativas.

El diagnóstico diferencial se plantea fundamentalmente con 3 cuadros clínicos. El primero es la mononucleosis infecciosa, pero en ésta los linfocitos son medianos y grandes, atipicos y las pruebas de aglutinación heterófila son positivas. En el examen físico destaca la pręsencia de adenopatias $y$ hepatoesplenomegalia.

En la coqueluche también hay leucocitosis con linfocitosis absoluta y relativa. Desde el punto de vista hematológico es nuy similar a la L A I, sin embargo, la intensidad de los síntomas respiratorios permite establecer la diferencia.

En la leucemia linfoblástica aguda, los linfoblastos pueden semejar linfocitos pequeños, pero se acompaña además de anemia y trombocitopenia.

No se ha logrado precisar la etiología de la L A I. Lo más probable es que se trate de una reacción hematológica a infecciones virales o bacterianas.

En los enfermos estudiados se han aislado Enterovirus ${ }^{6}$, Coxsackie $\mathrm{B}_{6}{ }^{7}$, Adenovirus tipo $5^{\mathbf{6}}$, Adenovirus tipo $12^{9}$, Coxsackie $A^{3}$. También podría encontrarse manifestaciones similares en infecciones bacterianas.

Además de las caracteristicas morfológicas, en el último tiempo ha parecido importante precisar el tipo de linfocito que aumenta en la L A I. Dadash Zaheđi ${ }^{10}$ estudió con técnicas de marcadores de membrana, los linfocitos de la LA I y encontró que el $50 \%$ eran linfocitos $\mathrm{T}$ y el resto era "null" (no B).

En la mononucleosis infecciosa, se ha compro- bado que aumentan los linfocitos $T$, además se ha demostrado que la célula infectada por virus Epstein-Barr es el linfocito B, sugiriendo que el aumento de linfocitos $T$ es una respuesta inmune efectiva frente a la infección por virus EpsteinBarr. Sin embargo, las características morfológicas de los linfocitos en la mononucleosis infecciosa, como ya dijimos, son muy diferentes a los de la L A l.

Se necesitan mayores estudios para precisar si los "null-cell" en L A I son linfocitos T o B inmaduros, o linfocitos que realizan cito-toxicidad mediada por reacción de anticuerpos.

Debido a que se trataría de una respuesta hematológica exagerada frente a infecciones virales o bacterianas y que podría tratarse de una enfermedad del linfocito, se ha sugerido que pudiesen aparecer secuejas hematológicas en el largo plazo, como leucemias u otras enfermedades hematológicas crónicas. Sin embargo, seguimientos de 20 años no han demostrado alteración alguna ${ }^{11}$. Queda por descartar a mayor plazo su relación con la leucemia linfática crónica.

\section{RESUMEN}

Se revisan los casos de tres pacientes con linfocitosis aguda infecciosa cuyo diagnóstico se fundamentó en el hallazgo de hiperleucocitosis en el hemograma, producida por la presencia de numerosos lífocitos pequeños, en nifios con un cuadro clínico de deposiciones liquidas, fiebre y ausencia de adenopatías y visceromegalia.

En los hemogramas, exceptuando la linfocitosis absoluta, no había otras alteraciones, salvo en un caso con anemia nutricional secundaria a enfermedad celíaca. El mielograma realizado en un caso, sólo mostro aumento del porcentaje de linfocitos pequeños.

El estudio virológico de secreción faríngea y deposiciones hecho en los niños fue negativo.

Los pacientes-tuvieron una rápida evolución clínica, mejoranda todos en el plazo de una semana. Los valores hematológicos se normaliza. ron antes de 3 semanas.

Estos hallazgos concuerdan con lo descrito en la literatura.

\section{REFERENCIAS}

' Carl Smith: Infectious lymphocytosis. Am. J. Dis. Child. 62: 231, 1941.

2 Scaletter H. y Cols.: Acute Infectious Lymphocy tosis. Am. J. Dis. Child. 88: 15, 1954.

${ }^{3}$ Horwitz $M$. Gordon $r_{\text {: }}$ Acute Infectious Lymphocitosis. Study of an New Engl. J. Med. 279: 399, 1968.

${ }^{4}$ Howard J.: Linfocitosis aguda infecciosa con lesiones de eritema multiforme. Rev. Child. Ped. 566, Dici. 1961. 
${ }^{5}$ Ryder R.J.W: Acute infectious lymphocitosis. Am. J. Dis. Child. 110: 299, 1965.

${ }^{6}$ Mandal B.K., Stokes K.J.: Acute infectious lymphocytosis and enterovirus. Lancet 2: 1392, 1973.

${ }^{7}$ Nkrumah $F_{\text {., }}$ Addy $P_{.:}$Acute infectious lymphocytosis. Lancet 1: 1257, 1973.

- Collier A. y cols.: Generalized type $S$ adenovirus infection associated with the pertussis syndrome. $J$. Pediat. 69: 1073, 1966.
${ }^{9}$ Olson L. y cols.: Acute infectious lymphacytosis presenting a pertussislike illnes: its association with adenovirus 12 Lancet. 1; 200, 1964.

10 Dadash-Zaueh y cols.: T. and null cell proliferation in a patient with acute infectious lymphocytosis. J. Pediat. 88: $520,1976$.

11 Pumam $S$. $y$ cols.: Infectious lymphocytosis long term follow up of an epidemic. Pediatrics 41: $588,1968$. 